\title{
Effects of processing parameters on the properties of amphiphilic block copolymer micelles prepared by supercritical carbon dioxide evaporation method
}

\author{
Zhen Jiao $^{1,2 *}$, Ziyi Wang ${ }^{1}$, Xiudong Wang ${ }^{1}$, Wenjing Fan ${ }^{1}$ \\ ${ }^{1}$ Southeast University, School of Chemistry and Chemical Engineering, Nanjing 211189, China \\ ${ }^{2}$ Joint Research Institute of Southeast University and Monash University, Center for Nanobiotechnology, Suzhou 215123, \\ China \\ "Corresponding authors: e-mail: jiaozhen@seu.edu.cn
}

\begin{abstract}
The operation parameters for the supercritical carbon dioxide $\left(\mathrm{ScCO}_{2}\right)$ evaporation method greatly affect the properties of the prepared drug-loaded micelles. In this study, the effects of those key parameters on the drug-loading content (LC) and drug entrapment efficiency (EE) are discussed. It is observed that EE and LC of the micelles are slightly increased with the enhancing temperature and the copolymer molecular ratio of hydrophilic/hydrophobic segment, while decreased with the enhancing $\mathrm{ScCO}_{2}$ evaporation rate. The pressure and volume ratio of $\mathrm{ScCO}_{2}$ to $\mathrm{H}_{2} \mathrm{O}$ are observed the optimum condition. In addition, the verification experiment is carried out under the obtained optimizing parameters. The prepared micelles exhibit relatively regular spherical shape and narrow size distribution with the EE and LC value of $70.7 \%$ and $14.1 \%$, respectively.
\end{abstract}

Keywords: supercritical carbon dioxide, amphiphilic block copolymer, drug-loaded micelles, processing parameters, optimization.

\section{INTRODUCTION}

Cancer is considered as one of the most lethal diseases in the world. The development of theranostics technique for cancer has been paid great attention ${ }^{1}$. Paclitaxel (PTX) is recognized as an efficient anticancer drug and demonstrated to have the inhibition of tumors ${ }^{2}$. In clinical trials, PTX shows significant activities against various tumors including head and neck cancer, refractory ovarian cancer, metastatic breast cancer and non-small cell lung cancer ${ }^{3,4}$. However, the biological application of PTX is limited due to its poor solubility, low bioavailability and problems on internal release ${ }^{5}$. In order to enhance the solubility and decrease its adverse effect, multifunctional drug delivery systems based on nanoparticles and polymers have been developed in the recent years ${ }^{6}$.

Owing to its unique and advanced features (e.g. easily available structure modification, effective targeting ability, retention effect and high permeability, as well as the ability of bypassing the detection of immune system), amphiphilic block copolymer micelles are demonstrated as the ideal drug delivery system ${ }^{7,8}$. In aqueous solution, amphiphilic block copolymers can self-assemble into polymeric micelles with hydrophobic core and hydrophilic shell. The lipophilic drugs can be effectively assembled in the hydrophobic core, while the hydrophilic shell enhancing the stability in vivo by making particles "invisible" after intravenous injection. A lot of literatures report that amphiphilic block copolymers have been successfully used as drug delivery systems. For example, Luo and Gu's group prepared a series of smart nanoparticles based on the self-assembly of amphiphilic block copolymers for cancer therapy ${ }^{9-13}$.

Emulsion solvent evaporation method is one of the most popular processes to prepare drug-loaded micelles using amphiphilic block copolymers. The most commonly used solvents are ethanol, chloroform, etc. However, the residual organic solvents in the micelles might cause serious side effects ${ }^{14-18}$.

Due to their low viscosity, high diffusivity, easily available critical point and low surface tension, supercritical fluids (SCFs) have been attached much attention ${ }^{19-22}$. Specially, supercritical carbon dioxide $\left(\mathrm{ScCO}_{2}\right)$ as a green solvent has been applied in a lot of processes ${ }^{23-26}$. In our previous study, the amphiphilic block copolymer micelles loaded PTX have been successfully prepared through solvent evaporation method using supercritical carbon dioxide instead of traditional organic solvents ${ }^{27}$. The drug loading content and encapsulation efficiency of the micelles prepared by this method are similar to those of the organic solvent-based method. It reveals that the supercritical carbon dioxide evaporation method is a novel way to prepare micelles and this approach is much friendly comparing to traditional ones.

Although the previous work successfully prepares the drug-loaded micelles by evaporation method using supercritical carbon dioxide, the effects of processing conditions on the prepared micelles is not discussed. In order to gain a deeper understanding of the characteristics of this process, the effects of the condition parameters including the temperature, pressure, copolymer molecular ratio of hydrophobic segment and hydrophilic one, evaporation rate, volume ratio of $\mathrm{ScCO}_{2}$ and $\mathrm{H}_{2} \mathrm{O}$ on the drug loading content(LC) and drug entrapment efficiency(EE) of the PTX-loaded micelles are discussed in details. Afterwards, the verification experiment is carried out under the optimizing parameters. The properties of the prepared micelles are determined to verify the obtained optimal conditions.

\section{EXPERIMENTAL}

\section{Material}

Vinyl acetate with a purity of $97 \%$ was purchased from Sinopharm Chemical Reagent Co. Ltd, China and used 
before passing through an alumina column to remove inhibitor. Ethyl 2-bromopropionate with A.R. grand and poly(ethylene glycol) methyl ether methacrylate (average $\mathrm{Mn}=300$ ) was purchased from Aldrich. 2,2-Azobisisobutyronitrile was obtained from Aldrich and used before recrystallizing three times using ethanol. Paclitaxel with a purity of $99.8 \%$ was obtained from Jiangsu Yew Pharmaceutical Co. Ltd, China. Carbon dioxide (99.99\% purity) was supplied by Nanjing Special Gases factory Co. Ltd.

\section{Synthesis of poly(vinyl acetate)-b-poly(ethylene glycol)} methyl ether methacrylate

The amphiphilic block copolymer, poly(vinyl acetate)-b-poly(ethylene glycol) methyl ether methacrylate (where poly(vinyl acetate) acts as $\mathrm{CO}_{2}$-philic block and poly(ethylene glycol) methyl ether methacrylate acts as hydrophilic one), is synthesized by RAFT polymerization via a three-step procedure. First, the selected RAFT agent for the preparation of VAc macroRAFT agent, (S)-2-(ethyl propionate)-(O-ethyl xanthate), is synthesized according to the work by Patel et al. ${ }^{28}$. Second, vinyl acetate, AIBN and (S)-2-(ethyl propionate)-(O-ethyl xanthate) are mixed to prepared VAc macroRAFT agent. The molecular weight of the product is determined by GPC. Third, VAc macroRAFT agent, AIBN and poly(ethylene glycol) methyl ether methacrylate (PEGMA) are reacted to form the final product. The molecular ratio of hydrophobic segment and hydrophilic one of the amphiphilic block copolymer, poly(vinyl acetate)- $b$-poly(ethylene glycol) methyl ether methacrylate (PVAC- $b$ -PEGMA), is calculated by ${ }^{1} \mathrm{HNMR}$, which are recorded in $\mathrm{CDCl}_{3}$ on a Bruker AVANCE300 $\mathrm{MHz}$ spectrometer using tetramethylsilane (TMS) as an internal reference at room temperature.

Preparation of the drug-loaded micelles by supercritical carbon dioxide evaporation method

A schematic representation of the apparatus used for the preparation of drug-loaded micelles by supercritical carbon dioxide evaporation method is shown in Figure 1. The setup consists mainly of nitrogen cylinder (A), carbon dioxide cylinder (B), high-pressure pumps (C), dissolution cell (D), micelle formation cell (E), water bath $(\mathrm{F})$, flowmeter $(\mathrm{G})$, control valves $(\mathrm{V})$ and pressure gauges $(\mathrm{P})$. The dissolution cell and micelle formation cell are produced by Haian Petroleum Technology Co., Ltd and their working pressure rang is $0-16 \mathrm{MPa}$. The high pressure pump is purchased from Beijing Xingda Technology Co., Ltd. The pressure of the system is monitored using a pressure transducer purchased from

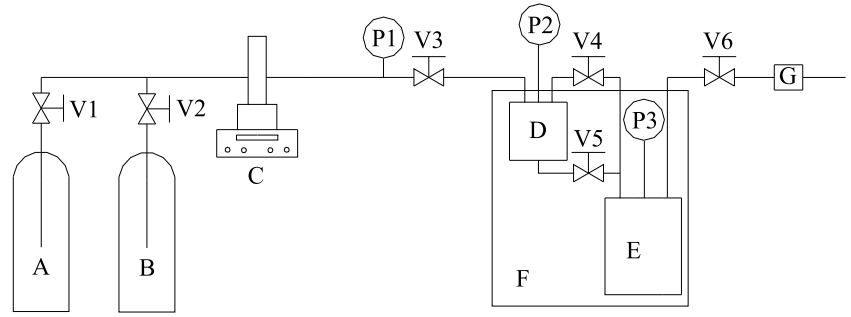

Figure 1. A schematic representation of the $\mathrm{ScCO}_{2}$ evaporation apparatus (A: nitrogen cylinder; $\mathrm{B}$ : carbon dioxide cylinder; C: high-pressure pumps; D: dissolution cell; E: micelle formation cell; F: water bath; G: flowmeter; V: control valves; P: pressure gauges)
Nanjing Keda Technology Co., Ltd. with $0.1 \%$ accuracy in the pressure of $0-30 \mathrm{MPa}$. The temperature of the water bath is controlled by an input type thermostat purchased from Beijing Changliu Scientific Instrument Co., Ltd and its accuracy is $\pm 0.1^{\circ} \mathrm{C}$.

During an experiment, paclitaxel is loaded into the dissolution cell. Copolymer and water are added into the micelle formation cell. The water bath is kept at a certain temperature during the preparation process. Then nitrogen from a cylinder is introduced into the system to control the added amount of $\mathrm{CO}_{2}$ in the next step. After that, carbon dioxide from another cylinder is pumped to the dissolution cell using the high pressure pump. After stirring for 4 hours to dissolve paclitaxel, the mixture in the dissolution cell is added to the micelle formation cell through valve 5 . The mixture in the micelle formation cell is stirred vigorously for 8 hours, then valve 6 is opened to evaporate the carbon dioxide and the drug loaded micelles are formed in the system. During the evaporation process, carbon dioxide evaporation rate is controlled by the flowmeter. Finally, the solution is centrifuged and is filtered to remove the unloaded drugs.

Table 1. Standard preparation parameters and their investigated range

\begin{tabular}{|c|c|c|}
\hline Parameters & Standard & Investigated range \\
\hline Copolymer composition & $\begin{array}{l}\text { PVAC }_{67-}-b- \\
\text { PEGMA }_{18}\end{array}$ & $\begin{array}{c}18-103 \\
{\left[\mathrm{DP}^{*} \text { of } \mathrm{PEGMA}\right]}\end{array}$ \\
\hline Temperature $\left[{ }^{\circ} \mathrm{C}\right]$ & 40 & $35-45$ \\
\hline Pressure $[\mathrm{MPa}]$ & 13.5 & $9.5-14.5$ \\
\hline $\begin{array}{l}\mathrm{ScCO}_{2} \text { evaporation rate } \\
{\left[\begin{array}{ll}\mathrm{L} & \left.\mathrm{min}^{-1}\right]\end{array}\right.}\end{array}$ & 30 & $10-40$ \\
\hline $\begin{array}{l}\text { Volume ratio of } \mathrm{ScCO}_{2} \\
\text { and } \mathrm{H}_{2} \mathrm{O}\end{array}$ & $1: 3$ & $1: 2-1: 3.5$ \\
\hline
\end{tabular}

${ }^{*} \mathrm{DP}$ : degree of polymerization.

In this study, the effects of processing parameters include temperature, pressure, copolymer molecular ratio of hydrophobic segment and hydrophilic one, evaporation rate of $\mathrm{CO}_{2}$, volume ratio of $\mathrm{ScCO}_{2}$ and $\mathrm{H}_{2} \mathrm{O}$ on $\mathrm{LC}$ and $\mathrm{EE}$ of the micelles are studied. The standard conditions for the micelle preparation and the investigated ranges are summarized in Table 1.

\section{Determination of drug-loading content(LC) and drug entrapment efficiency(EE)}

The drug-loading content (LC) and drug entrapment efficiency (EE) of the micelles are determined using UV spectrophotometer. Specifically, the different concentration of paclitaxel ethanol solution is measured by UV spectrophotometer at the wavelength of $228 \mathrm{~nm}$ to obtain a calibration curve. Then, the drug-loaded micelle solution is filtered to collect the unloaded paclitaxel and dissolved it in ethanol. The content of this solution is calculated by the calibration curve and used to determine the entrapped amount of drug. The LC and EE of the micelles are calculated by the following equations:

$$
\begin{aligned}
& \mathrm{LC}=\frac{\text { Total amount of drug }- \text { entrapped amount of drug }}{\text { Total amount of micelles }} \times 100 \% \\
& \mathrm{EE}=\frac{\text { Total amount of drug }- \text { entrapped amount of drug }}{\text { Total amount of drug }} \times 100 \%
\end{aligned}
$$




\section{Morphology measurements of the micelles}

A JEOL JEM-200CX transmission electron microscope (TEM) is used to observe the morphology of the drug-loaded micelles. The detailed experimental process can be found in our previous manuscript ${ }^{29}$.

\section{RESULTS AND DISCUSSION}

\section{Device repeatability verification}

Verifying the repeatability of the process is quite prerequisite. Therefore, the verification experiment under the standard conditions is carried out before optimization determination. The results show that the difference of EE of the prepared micelles is within $\pm 0.5 \%$ in 5 repeated experiments, indicating a good repeatability of the process.

\section{Effect of block copolymer compositions}

Table 2 indicates that the EE and LC of the micelles are decreased with the increasing ratio of the hydrophilic segment of the copolymer. For the drug-loaded micelles, the drug is aggregated in the core by the interaction between the hydrophobic segment and the drug. The higher ratio of the hydrophobic segment in the copolymer motivates the drug aggregation in the micelles and employs the higher EE and LC of the micelles. The same conclusion can be found in the literatures which reported the preparation of the drug-loaded micelles using amphiphilic block polymer by organic solvent evaporation method ${ }^{29-31}$.

\section{EFFECT OF TEMPERATURE}

The experiments are determined at the temperature of 35,40 and $45^{\circ} \mathrm{C}$. It can be observed from Figure 2 that the LC and EE are slightly increased with the enhancing temperature. For the traditional organic solvent evaporation method, the effect of temperature on the properties of the micelles is reflected in two aspects. On one hand, temperature can affect the physical and chemical properties of the solution. On the other hand, the evaporation rate of the organic solvent is depended on the system temperature. For $\mathrm{ScCO}_{2}$ evaporation method, the evaporation rate of $\mathrm{CO}_{2}$ is controlled by the flowmeter. Thus the temperature of the system only affects the physical and chemical properties of the solution system. Specifically, the increased temperature can improve the solubility of drug and the hydrophilic segment of the copolymer in $\mathrm{ScCO}_{2}$. That could improve the stability of the micelles in the system and promote the aggregation of the drug in the nucleus of the micelle, resulting in the slightly increasing $\mathrm{EE}$ and $\mathrm{LC}$ of the prepared micelles.

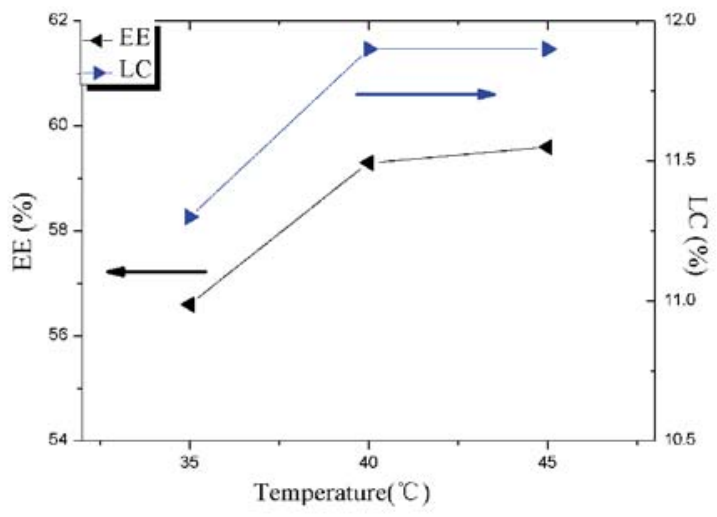

Figure 2. Effect of temperature on drug entrapment efficiency(EE) and drug-loading content(LC) of the micelles

\section{Effect of pressure}

The preparation pressures are selected from 9.5 to 14.5 $\mathrm{MPa}$ and the results are illustrated in Figure 3. It can be observed that the increasing pressure from 9.5 to $11.5 \mathrm{MPa}$ leads to higher EE and LC, while further increase shows the opposite trend. To our knowledge, higher pressure can increase the solubility of drug and the hydrophilic segment of the copolymer in $\mathrm{ScCO}_{2}$, which leads to the higher EE and LC. At the same time, the higher pressure means that more amount of carbon dioxide exists in the system to the same volume of $\mathrm{ScCO}_{2}$. As the release of carbon dioxide may bring a little amount drug out of the micelles, the increased release mass of carbon dioxide will cause a decrease of EE and LC. With the contribution of the two aspects, $\mathrm{EE}$ and LC of the micelles prepared in this study are observed the optimal values under the pressure of about 11.5 MPa.

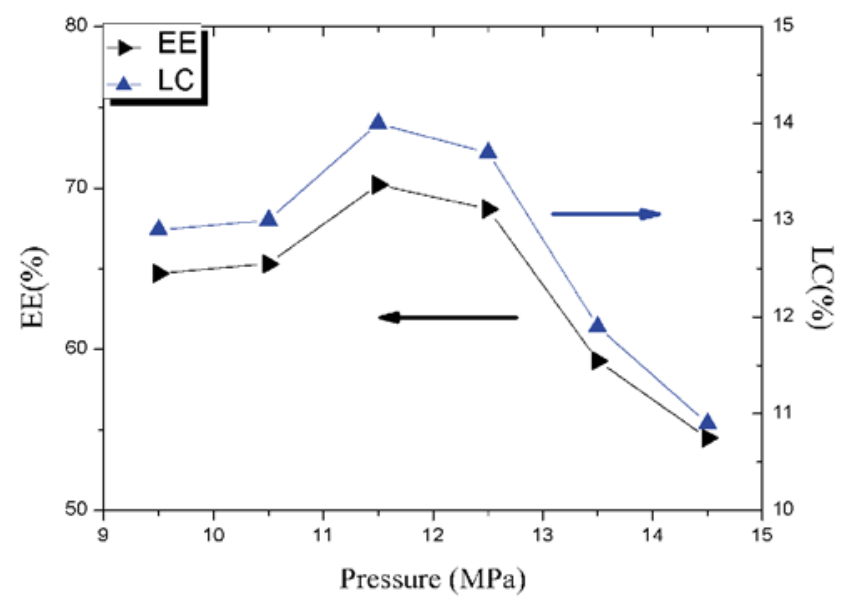

Figure 3. Effect of pressure on drug entrapment efficiency(EE) and drug-loading content(LC) of the micelles

Figure 4 shows the effect of evaporation rate on EE and LC of the micelles. The experimental range is from 10 to $40 \mathrm{~L} \mathrm{~min}{ }^{-1}$. It is observed that the $\mathrm{EE}$ and $\mathrm{LC}$ decrease with the faster evaporation rate within the experimental range. During the evaporation process, the

Table 2. Effect of copolymer compositions on EE and LC of the micelles

\begin{tabular}{|l|c|c|c|c|}
\hline Copolymers & DP of PVAc & DP of PEGMA & EE [\%] & LC [\%] \\
\hline PVAC $_{67}-b-$ PEGMA $_{18}$ & 67 & 18 & 55.4 & 11.9 \\
PVAC $_{67}-b-$ PEGMA $_{51}$ & 67 & 51 & 56.1 & 11.2 \\
PVAC $_{67}-b-$ PEGMA $_{103}$ & 67 & 103 & 59.3 & 11.1 \\
\hline
\end{tabular}




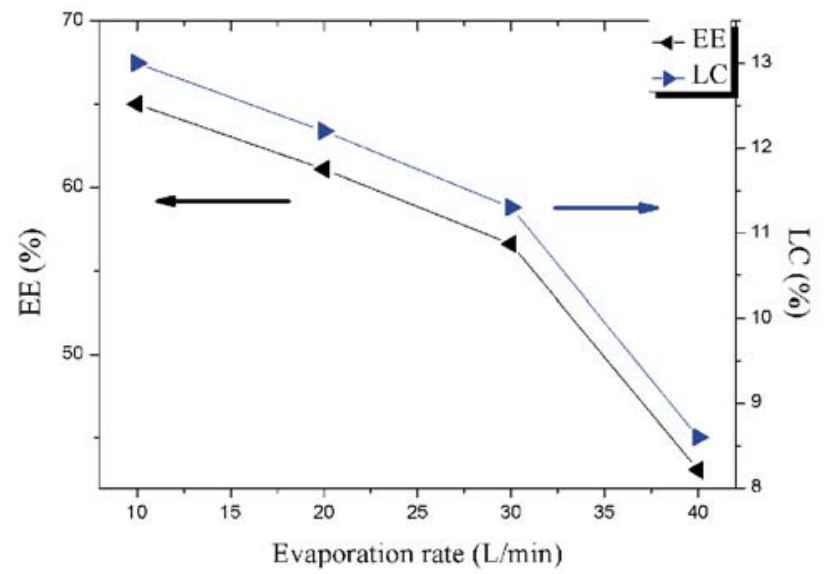

Figure 4. Effect of $\mathrm{ScCO}_{2}$ evaporation rate on drug entrapment efficiency(EE) and drug-loading content(LC) of the micelles

$\mathrm{CO}_{2}$ mass transfer procedure from the core of micelles may take some drug out of the micelles and the faster evaporation rate may lead to the enhanced drug escaping amount from the micelles. This can explain the results that the EE and LC of the micelles decrease with the increased evaporation rate. Remarkably, when the evaporation rate is faster than $40 \mathrm{~L} \mathrm{~min}^{-1}$, the air-aqueous solution interface of the system is very unstable during the evaporation process. Some water ever spills out of the solution at the fast evaporation rate. Therefore, the preparation process should be controlled under a suitable $\mathrm{CO}_{2}$ evaporation rate.

\section{Effect of volume ratio of $\mathrm{ScCO}_{2}$ and $\mathrm{H}_{2} \mathrm{O}$}

The effect of the volume ratio of $\mathrm{ScCO}_{2}$ and $\mathrm{H}_{2} \mathrm{O}$ is shown in Figure 5. The observed optimum volume ratio of $\mathrm{ScCO}_{2}$ and $\mathrm{H}_{2} \mathrm{O}$ is $1: 3$. This parameter plays a complicated effect on the EE and LC of the micelles. Specifically, more $\mathrm{ScCO}_{2}$ in the system can effectively improve its solubility capacity of the drug and the hydrophilic segment of copolymer, which leads to the higher EE and LC. However, the improved evaporation mass of carbon dioxide will cause a decreasing EE and LC because the evaporation process may bring a little amount of drug out of the micelles.

In addition, the properties of the system (e.g. viscosity and stability of the emulsion) are also changed with the different volume ratio. Those differences also affect the

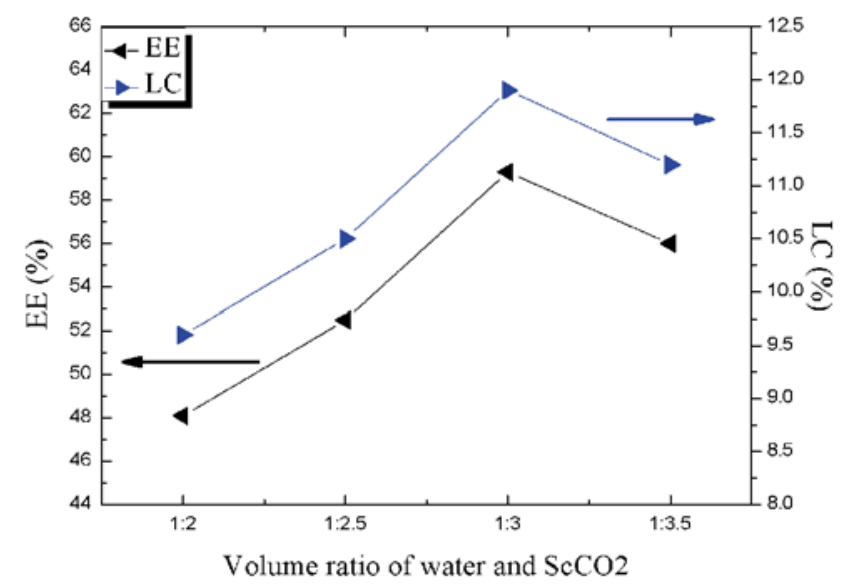

Figure 5. Effect of volume of $\mathrm{ScCO}_{2}$ phase on drug entrapment efficiency(EE) and drug-loading content(LC) of the micelles
EE and LC of the prepared micelles. In summary, these reasons lead to the optimum volume ratio of $\mathrm{ScCO}_{2}$ to $\mathrm{H}_{2} \mathrm{O}$ as 1:3. The similar results are found by the literature, which prepares polyester microspheres containing somatostatin acetate by solvent evaporation method using methylene chloride as solvent ${ }^{32}$.

\section{Verification experiment under the optimizing parameters}

In short, the optimizing parameters of the process are determined as follows: the temperature is $45^{\circ} \mathrm{C}$, the pressure is $11.5 \mathrm{MPa}$, the block copolymer is $\mathrm{PVAC}_{67}-b$ $-\mathrm{PEGMA}_{18}$, the evaporation rate of $\mathrm{CO}_{2}$ is $10 \mathrm{~L} \mathrm{~min}^{-1}$ and the volume ratio of $\mathrm{ScCO}_{2}$ to $\mathrm{H}_{2} \mathrm{O}$ is 1:3. The verification experiment is carried out under the optimizing parameters. The EE and LC of the prepared micelles are $70.7 \%$ and $14.1 \%$, which is obviously enhanced compared with the results of our previous paper (EE is $61.0 \%$ and LC is $12.2 \%)^{27}$. Figure 6 shows the morphology of the micelles prepared under optimizing parameters. The TEM image clearly shows that the micelles exhibit a narrow size distribution and relatively regular spherical shape. These results further verify that the drug loaded micelles are successfully prepared with fine morphology as well as the acceptable EE and LC.

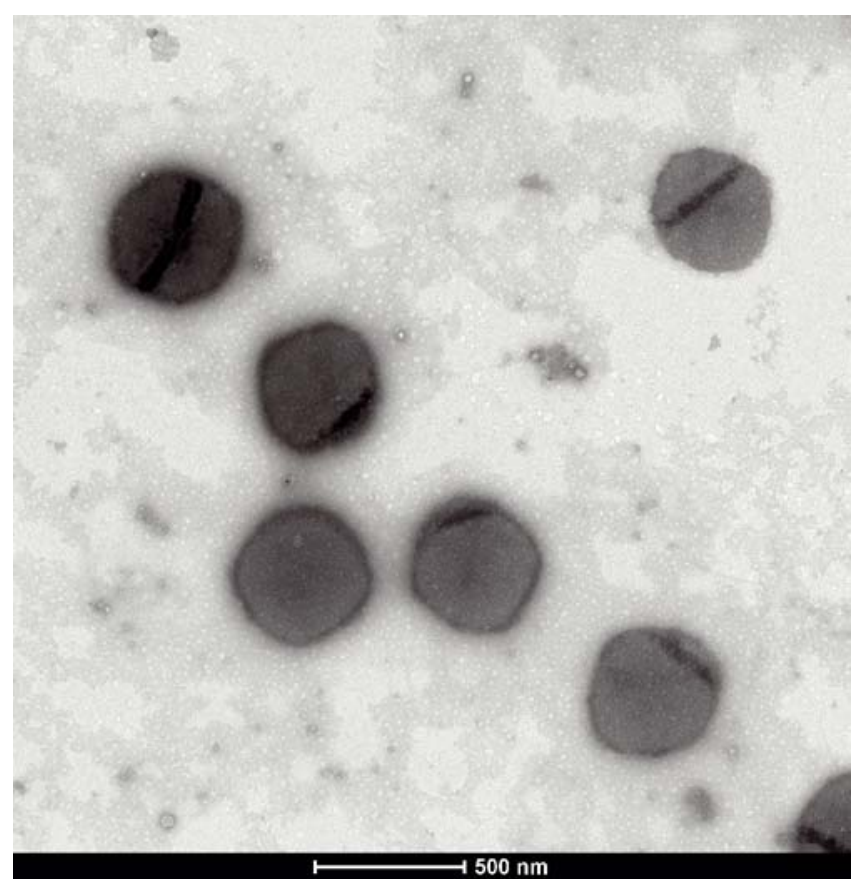

Figure 6. TEM image of drug-loaded micelles prepared under optimizing parameters

\section{CONCLUSION}

The amphiphilic block copolymer drug-loaded micelles are successfully prepared using the system, in which water acts as the continuous phase and supercritical carbon dioxide $\left(\mathrm{ScCO}_{2}\right)$ as the dispersed one. The effects of processing parameters on the properties of the prepared micelles are studied. The experimental results indicate that EE and LC slightly increase with the enhancing temperature and copolymer molecular ratio of hydrophilic segment to hydrophobic one in the experimental range, while decrease with the enhancing $\mathrm{ScCO}_{2}$ evaporation rate. The results also reveal that pressure and volume ratio of $\mathrm{ScCO}_{2}$ and $\mathrm{H}_{2} \mathrm{O}$ obtain the optimum point. The optimal EE and LC are observed at the conditions 
that the temperature is $45^{\circ} \mathrm{C}$, the pressure is $11.5 \mathrm{MPa}$, evaporation rate of $\mathrm{CO}_{2}$ is $10 \mathrm{~L} \mathrm{~min}^{-1}$, the volume ratio of $\mathrm{ScCO}_{2}$ to $\mathrm{H}_{2} \mathrm{O}$ is $1: 3$ and the used block copolymer is $\mathrm{PVAC}_{67}-b$ - $\mathrm{PEGMA}_{18}$. The verification experiment is carried out under the obtained optimizing parameters. The prepared micelles exhibit relatively regularly spherical shape and a narrow size distribution. The EE and LC of the micelles are $70.7 \%$ and $14.1 \%$.

\section{ACKNOWLEDGEMENTS}

This study is supported by National Science Foundation of Jiangsu Province (BK20130602), Collaborative Innovation Center of Suzhou Nano Science and Technology, the Priority Academic Program Development of Jiangsu Higher Education Institutions and the Fundamental Research Funds for the Central Universities.

\section{LITERATURE CITED}

1. Yang, X.Y., Zhang, X.Y., Liu, Z.F., Ma, Y.F., Huang, Y. \& Chen, Y. (2008). High-Efficiency Loading and Controlled Release of Doxorubicin Hydrochloride on Graphene Oxide. J. Phys. Chem. C 112, 17554-17558. DOI: 10.1021/jp806751k.

2. Chen, M.X., Li, B.K., Yin, D.K., Liang, J., Li, S.S. \& Peng, D.Y. (2014). Layer-by-layer Assembly of Chitosan Stabilized Multilayered Liposomes for Paclitaxel Delivery. Carbohydr. Polym. 111, 298-304. DOI: 10.1016/j.carbpol.2014.04.038.

3. Sugahara, K.N., Teesalu, T., Karmali, P.P., Kotamraju, V.R., Agemy, L., Greenwald, D.R. \& Ruoslahti, E. (2010). Coadministration of a Tumor-Penetrating Peptide Enhances the Efficacy of Cancer Drugs. Science 328, 1031-1035. DOI: 10.1126/science.1183057.

4. Ferrari, M. (2005). Cancer Nanotechnology: Opportunities and Challenges. Nat. Rev. Cancer 5, 161-171. DOI: 10.1038/ nrc1566.

5. Jin, J., Lee, W.S., Joo, K.M., Maiti, K.K., Biswas, G., Kim, W., Kim, K.T., Lee, S.J., Kim, K.H., Nam, D.H. \& Chung, S.K. (2011). Preparation of Blood-brain Barrier-permeable Paclitaxel-carrier Conjugate and Its Chemotherapeutic Activity in The Mouse Glioblastoma Model. Med. Chem. Comm. 2, 270-273. DOI: $10.1039 / \mathrm{c} 0 \mathrm{md} 00235 \mathrm{f}$.

6. Brannon-Peppas, L. \& Blanchette, J.O. (2004). Nanoparticle and Targeted Systems for Cancer Therapy. Adv. Drug. Deliv. Rev. 64, 206-212. DOI: 10.1016/j.addr.2012.09.033.

7. Torchilin, V.P. (2007). Micellar nanocarriers: Pharmaceutical Perspectives. Pharm. Res. 24, 1-16. DOI: 10.1007/ s11095-006-9132-0.

8. Kataoka, K., Harada, A. \& Nagasaki, Y. (2001). Block Copolymer Micelles for Drug Delivery: Design, Characterization and Biological Significance. Adv. Drug Deliv. Rev. 47, 113-131. DOI: 10.1016/S0169-409X(00)00124-1.

9. Yang, Y., Pan, D., Luo, K., Li, L. \& Gu, Z. (2013). Biodegradable and amphiphilic block copolymer-doxorubicin conjugate as polymeric nanoscale drug delivery vehicle for breast cancer therapy. Biomaterials 34, 8430-8443. DOI: 10.1016/j. biomaterials.2013.07.037.

10. Li, N., Li, N., Yi, Q., Luo, K., Guo, C., Pan, D. \& Gu, Z. (2014). Amphiphilic peptide dendritic copolymer-doxorubicin nanoscale conjugate self-assembled to enzyme-responsive anti-cancer agent, Biomaterials, 35, 9529-9545. DOI: 10.1016/j. biomaterials.2014.07.059.

11. Li, N., Guo, C., Duan, Z., Yu, L., Luo, K., Lu, J. \& Gu, Z. (2016). A stimuli-responsive Janus peptide dendron-drug conjugate as a safe and nanoscale drug delivery vehicle for breast cancer therapy. J. Mater. Chem. B, 4, 3760-3769. DOI: 10.1039/c6tb00688d.

12. Li, N., Cai, H., Jiang, L., Hu, J., Bains, A., Hu, J., Gong, Q., Luo, K. \& Gu, Z. (2017). Enzyme-Sensitive and Amphiphilic
PEGylated Dendrimer-Paclitaxel Prodrug-Based Nanoparticles for Enhanced Stability and Anticancer Efficacy ACS Appl. Mater. Inter. 9, 6865-6877. DOI: 10.1021/acsami.6b15505.

13. Duan, Z.Y., Zhang, Y.H., Zhu, H.Y., Sun, L., Cai, H., Li, B.J., Gong, Q.Y., Gu, Z. W. \& Luo, K. (2017). Stimuli-Sensitive Biodegradable and Amphiphilic Block Copolymer-Gemcitabine Conjugates Self-Assemble into a Nanoscale Vehicle for Cancer Therapy, ACS Appl. Mater. Inter. 9, 3474-3486. DOI: 10.1021/ acsami.6b15232.

14. Torchilin, V.P. (2001). Structure and Design of Polymeric Surfactant-based Drug Delivery Systems, J. Control. Release 73, 137-172. DOI: 10.1016/S0168-3659(01)00299-1.

15. Riess, G. (2003). Micellization of Block Copolymers. Prog. Polym. Sci. 28, 1107-1170. DOI: 10. 1016/S00796700(03)00015-7.

16. Tucker, B.S. \& Sumerlin, B.S. (2014). Poly(N-(2-hydroxypropyl) methacrylamide)-based Nanotherapeutics. Polym. Chem. 5, 1566-1572. DOI: 10.1039/C3PY01279D.

17. Gaucher, G., Marchessault, R.H. \& Leroux, J.C. (2010). Polyester-based Micelles and Nanoparticles for the Parenteral Delivery of Taxanes. J. Control. Release 143, 2-12. DOI: 10.1016/j.jconrel.2009.11.012.

18. Odonnell, P.B. \& McGinity, J.W. (1997). Preparation of Microspheres by the Solvent Evaporation Technique. Adv. Drug. Deliv. Rev. 28, 25-42. DOI: 10.1016/S0169-409X(97)00049-5.

19. Blackburn, J.M., Long, D.P., Cabanas, A. \& Watkins, J.J. (2001). Deposition of Conformal Copper and Nickel Films From Supercritical Carbon Dioxide. Science 294, 141-145. DOI: 10.1126/science.1064148.

20. Darr, J.A. \& Poliakoff, M. (1999). New Directions in Inorganic and Metal-organic Coordination Chemistry in Supercritical Fluids. Chem. Rev. 99, 495-541. DOI: 10.1021/cr970036i.

21. Pham, Q.L., Nguyen, V.H., Haldorai, Y. \& Shim, J.J. (2013). Polymerization of Vinyl Pivalate in Supercritical Carbon Dioxide and the Saponification for the Preparation of Syndiotacticity-rich Poly(vinyl alcohol). Korean J. Chem. Eng. 30, 1153-1161. DOI: 10.1007/s11814-013-0019-6.

22. Kendall, J.L., Canelas, D.A., Young. J.L. \& DeSimone, J.M. (1999). Polymerizations in Supercritical Carbon Dioxide. Chem. Rev. 99, 543-563. DOI: 10.1021/cr9700336.

23. Meng, Y., Su, F.H. \& Chen, Y.Z. (2015). A Novel Nanomaterial of Graphene Oxide Dotted with Ni Nanoparticles Produced by Supercritical $\mathrm{CO}_{2}$-Assisted Deposition for Reducing Friction and Wear. ACS Appl. Mater. Interf. 7, 11604-11612. DOI: 10.1021 /acsami.5b02650.

24. Islam, M.N., Haldorai, Y., Nguyen, V.H. \& Shim, J.J. (2014). Synthesis of Poly(vinyl pivalate) by Atom Transfer Radical Polymerization in Supercritical Carbon Dioxide. Eur. Polym. J. 61, 93-104. DOI: 10.1016/j.eurpolymj.2014.09.003.

25. Baldino, L., Sarno, M., Cardea, S., Irusta, S., Ciambelli, P., Santamaria, J. \& Reverchon, E. (2015). Formation of Cellulose Acetate-Graphene Oxide Nanocomposites by Supercritical $\mathrm{CO}_{2}$ Assisted Phase Inversion. Ind. Eng. Chem. Res. 54, 8147-8156. DOI: 10.1021/acs.iecr.5b01452.

26. Nguyen, V.H., Haldorai, Y., Pham, Q.L. \& Shim, J.J. (2011). Supercritical Fluid Mediated Synthesis of Poly(2-hydroxyethyl methacrylate) $/ \mathrm{Fe}_{3} \mathrm{O}_{4}$ Hybrid Nanocomposite. Mater. Sci. Eng. B-Adv. Funct. Solid-State Mater. 176, 773-778. DOI: 10.1016/j.mseb.2011.02.020.

27. Jiao, Z., Liu, N. \& Chen, Z.M. (2012). Selection Suitable Solvents to Prepare Paclitaxel-loaded Micelles by Solvent Evaporation Method. Pharm. Dev. Technol. 17, 164-169. DOI: 10.3109/10837450.2010.529146.

28. Patel, V.K., Vishwakarma, N.K., Mishra, A.K., Biswas, C.S. \& Ray, B. (2012). (S)-2-(ethyl propionate)-(O-ethyl xanthate)- and (S)-2-(Ethyl isobutyrate)-(O-ethyl xanthate)-mediated RAFT Polymerization of Vinyl Acetate. J. Appl. Polym. Sci. 125, 2946-2955. DOI: 10.1002/app.36233.

29. Chu, H.Y., Liu, N., Wang, X., Jiao, Z. \& Chen, Z.M. (2009). Morphology and in vitro Release Kinetics of Drug- 
-loaded Micelles Based on Well-defined PMPC-b-PBMA Copolymer. Int. J. Pharm. 371, 190-196. DOI: 10.1016/j. ijpharm.2008.12.033.

30. Allen, C., Maysinger, D. \& Eisenberg, A. (1999). Nano-engineering Block Copolymer Aggregates for Drug Delivery. Coll. Surf. B-Biointerfaces 16, 3-27. DOI: 10.1016/S09277765(99)00058-2.

31. Rapoport, N. (2007). Physical Stimuli-responsive Polymeric Micelles for Anti-cancer Drug Delivery. Prog. Polym. Sci. 32, 962-990. DOI: 10.1016/j.progpolymsci.2007.05.009.

32. Herrmann, J. \& Bodmeier, R. (1995). Somatostatin Containing Biodegradable Microspheres Prepared by a Modified Solvent Evaporation Method Based on W/O/W-multiple Emulsions. Int. J. Pharm. 126, 129-138. DOI: 10.1016/03785173(95)04106-0. 